\title{
Wind energy state of the art: present and future technology advancements ${ }^{\star}$
}

\author{
Abdul Salam Darwish ${ }^{1, *}$ and Riadh Al-Dabbagh ${ }^{2}$ \\ ${ }^{1}$ School of Civil Engineering, University of Bolton, Bolton, UK \\ 2 Ajman University, Ajman, UAE
}

Received: 21 December 2019 / Accepted: 7 February 2020

\begin{abstract}
Renewables today are the first-choice option for a modern power system. Wind and solar are now competitive with conventional sources and commanded a high percentage of investments in renewable power. The cost of wind turbines has fallen by nearly $1 / 3 \mathrm{rd}$ since 2009 and that of solar photovoltaic (PV) modules by $80 \%$. The number of countries that held auctions to deploy renewables has increased (from 6 in 2005 to 67 countries in 2017) with a very large increase in global investment. Global cumulative installed wind power capacity had more than $645 \mathrm{GW}$ by the first quarter of 2019. The paper reviews the recent developments in wind energy conversion systems technology and discusses future expectations. Offshore wind turbines are the most possible technology for future utilization and of this, floating wind turbines are to dominate with larger scales could reach three times the present introduced scales. This is to provide more than $20 \%$ of the global demand in 2030. The paper presents several case studies for each case and highlights the technological aspects that support each development. The most important design advancements are also discussed with a forecast of the future design expectation that will affect the wind power generation program.
\end{abstract}

\section{Introduction}

Renewables nowadays is the first choice to be considered as alternative energy when power systems need to be upgraded and developed. $90 \%$ of those renewables are in the form of solar and wind. Investments in these two sources have been sharply increasing and competitive with conventional sources of electricity. Wind energy systems' cost has been continuously. This has been reflected in the cost of electricity. Climate change associated consequences have been imposing high pressure on Governments to start looking for alternatives and sustainable energy developments reducing the carbon footprint and emission. In response, there has been a significant increase in the number of auctions held for these systems, from 6 in 2005 to more than 67 in 2017 [1]. Renewable energy investment has reached more than USD 289 billion of which USD 134.1 billion for wind energy. This has exceeded the investment in fossil fuel [2]. Worldwide renewable jobs have considerably increased and reached more than 11 million people in 2018. China was the largest followed by

\footnotetext{
* World renewable Energy Congress "Green Colombo" $30^{\text {th }}$ September to $4^{\text {th }}$ October 2019.

* e-mail: a.darwish@bolton.ac.uk
}

the EU, Brazil, the US, and India, as illustrated in Figure 1 which shows the number of jobs offered by renewable energy implementation reached to more than 11 Million jobs in 2018 [3].

Wind power installations sharply increased in recent years. The development and advancements in wind power generation systems were at high levels and shown worldwide interest. Figure 2 shows the global cumulative installed wind power capacity (MW) $[4,5]$.

Reference [4] found that the accumulative installed wind power capacity reached $599 \mathrm{GW}$ in 2018, and this has been increased by $7 \%$ in 2019 to reach $645 \mathrm{GW}$ [5].

Wind energy associated system technology development needs to be sustainable in order to support climate mitigation, economic benefits, and energy security [6]. Wind energy has a global technical potential five times the current global energy production (i.e. forty times the global electricity demand with the best-assumed scenario [7].

In this paper, it is aimed to the present status of renewables and specifically wind energy developments and to overlook the future of wind energy with the latest technology advancements. The research is to present the most promising technology i.e. the floating wind system as the future practical system for implementations. 
Jobs in Renewable Energy

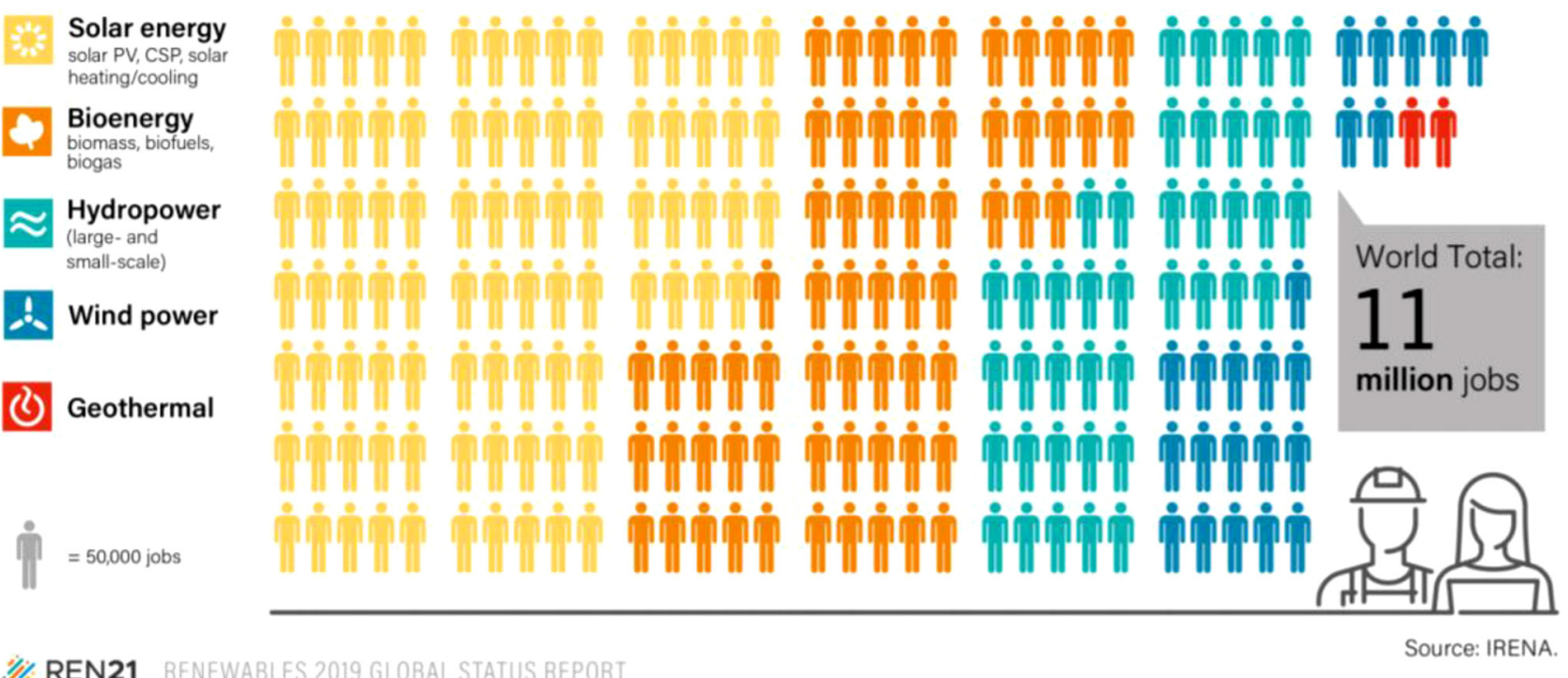

Fig. 1. Jobs in renewable energy 2018 [3].

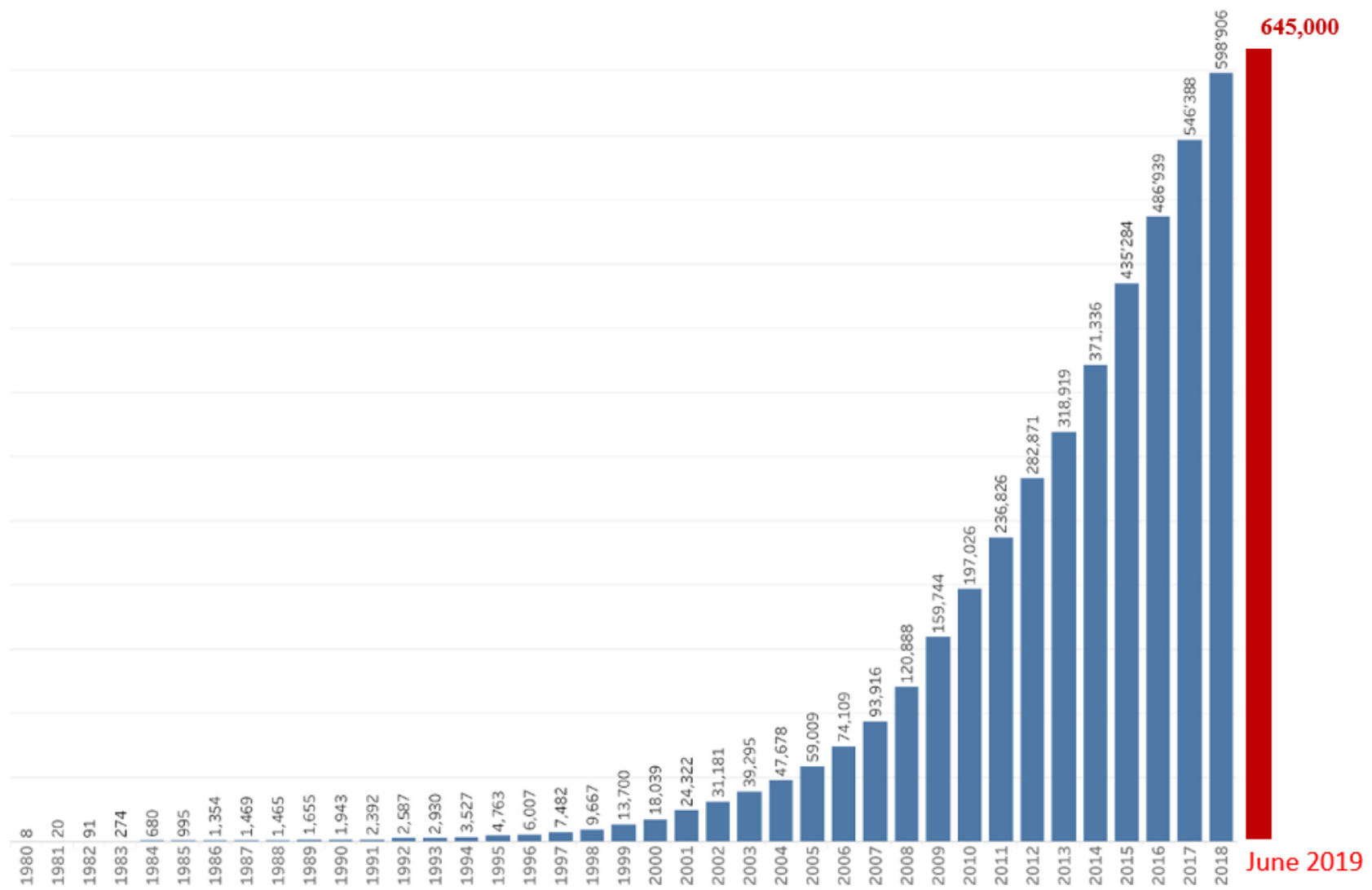

Fig. 2. Global cumulative installed wind power capacity (MW) $[4,5]$.

\section{Wind power to dominate power sector growth}

Different scenarios were outlined by the Global Wind Energy Council to suggest that wind energy systems could provide $20 \%$ of the global demand for electricity by
2030 [8]. As the Paris Agreement targets state a completely decarbonised electricity supply before 2050, wind energy will have a major role on this target.

2110 GW generated capacity could be reached by 2030 which would be equivalent to $20 \%$ of the Global needs. It is expected to create more than 2.4 million jobs with 3.3 


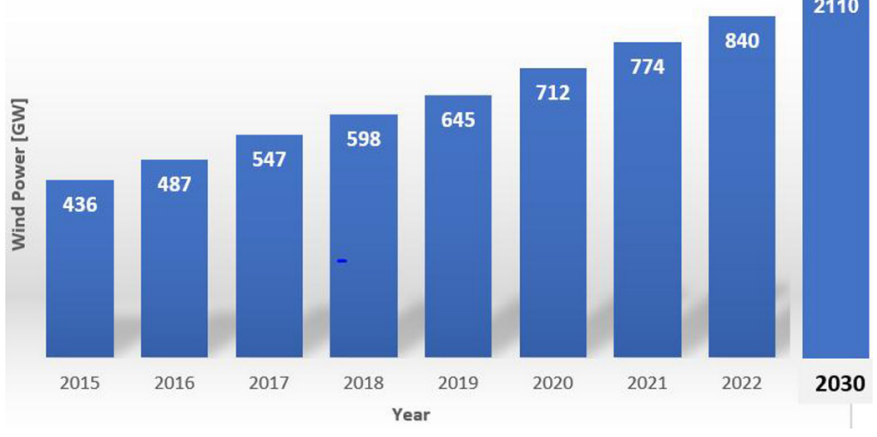

Fig. 3. Expected cumulative generated capacity in 2030 In GW [8].

billion tonnes of $\mathrm{CO}_{2}$ emissions a year. An investment which reaches about $€ 200$ billion is expected within ten years [8]. This is to be supported by many key factors such as the dramatic decrease in the wind energy systems price which brightens the feasibility of the deployment of such systems which make it economically competitive. In addition, the recent advancement in those technologies and the developments in the smart grids could well be the new battery storage achievements. Therefore, an increased movement towards growing the market for electric vehicles as well as public transport increasing the future demand for electricity. Wind energy power systems are more likely able to supply this electricity demand, Figure 3 shows the predicted and expected cumulative generated capacity in 2030 [8].

\section{Global wind energy systems' market}

Global wind energy systems' market in comparison with other renewable energy sources can be seen in Figure 4 [5].

It is clear from Figure 4 that, a continuous steep cost reduction curve. Solar and wind power generation costs are significantly lower than nuclear, gas and coal plants. 2018 showed a considerable increasing number of contracts in both sources is noticed. Special support from international lenders has recently intensified for the developing countries.

\section{Wind roadmap targets}

Wind roadmap target is presented in Figure 5 which shows the wind regional wind electricity production to 2050 (TWh) [9].

It is clear from Figure 5 that the Wind is expected to have the potential to provide $20 \%$ of global electricity production in 2050. In this respect the Global Wind Energy Council (GWEC) [10], envisions 5.8 TW of wind by 2050. GWEC anticipated that China would remain the world's largest market with $1789 \mathrm{GW}$ of wind power by 2050, North America - including the US, Canada and Mexico combining to have $919 \mathrm{GW}$ and OECD Europe could have
703 GW of wind by 2050. In addition, Latin America predicted to generate (481 GW) and India (452 GW) [10]. Two scenarios (Moderate and Advanced) for the regional breakdown presented in Figure 6 .

\section{World electricity demand scenarios 2050}

Many scenarios and plans in different countries suggested that in the future up to $40 \%$ wind penetration can be safely assumed by the year 2050 ([11], pp. 42). In this respect, electricity consumption will not increase to as high a value as $74000 \mathrm{TWh} / \mathrm{yr}$ but remains at a low of $40000 \mathrm{TWh} / \mathrm{yr}$. The expected reasons are ([11], pp. 42):

- significantly increased energy efficiency,

- climate change,

- significant variations in trends due to social, political and economic reasons,

- technological development and other competing technologies, etc.

Scenarios such as LOW, LIKELY, or HIGH could well be considered that wind power generation could vary from the highest expected point to a rather low point. Table 1 summarises the World Electricity Demand scenarios 2050 ([11], pp. 42).

\section{Renewable energy and energy efficiency can provide over $90 \%$ of the reduction in energy-related $\mathrm{CO}_{2}$ emissions}

A reference case mentioned by the International Renewable Energy Agency (IRENA) analysis has expected a slight increase in energy-related $\mathrm{CO}_{2}$ emissions until 2040 then slightly dipping by 2050 to today's level, see Figure 7 [12]. IRENA's analysis has concluded that renewable energy and energy efficiency, coupled with deep electrification of end-uses, can provide over $90 \%$ of the reduction in energy-related $\mathrm{CO}_{2}$ Emissions and the remainder would be achieved by fossil fuel switching.

\section{Future of wind energy in Europe}

Figure 8 shows a total of wind power generation installed up to 2018 was $178.8 \mathrm{GW}$ [13]. This has increased to 183.7GW by 2019 overtaken the Natural Gas.

The combined installations of onshore and offshore wind capacity in Europe was the same as in 2018 but onshore was down. Table 2 shows the wind energy installed capacity by country in 2019 , which shows a total of $4.9 \mathrm{GW}$ [14].

Scenarios were published by EWEA (European Wind Energy Association) [15], for the future of wind energy installed and implemented technology in Europe and emphasised that wind energy's potential in 2030 will depend to a large extent on recent policy developments in the major EU climate and energy priorities. The EWEA's position on EU energy and climate priorities are related to [15]: 


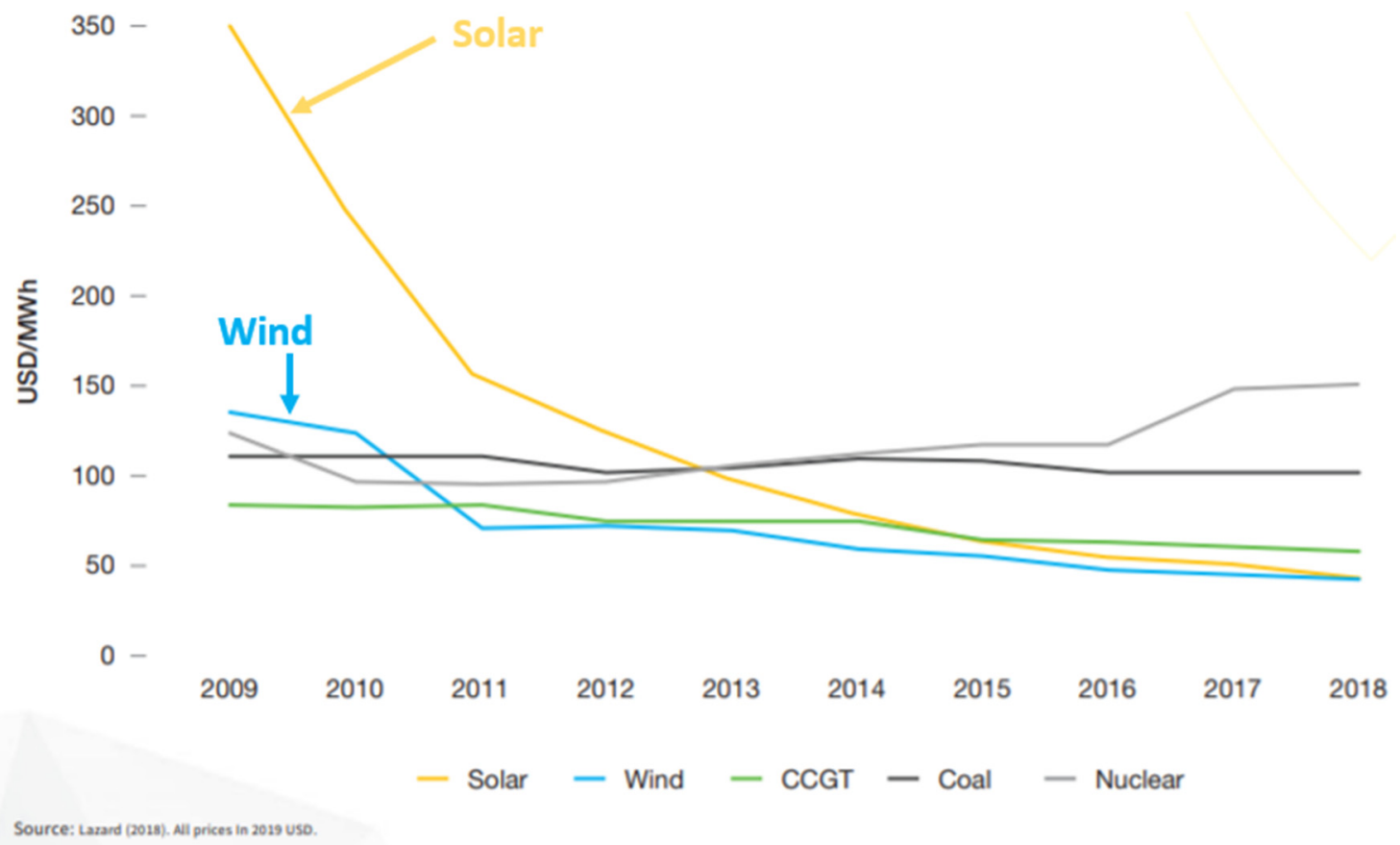

Fig. 4. Wind electricity generation cost in comparison with other power sources 2009-2018 [5].

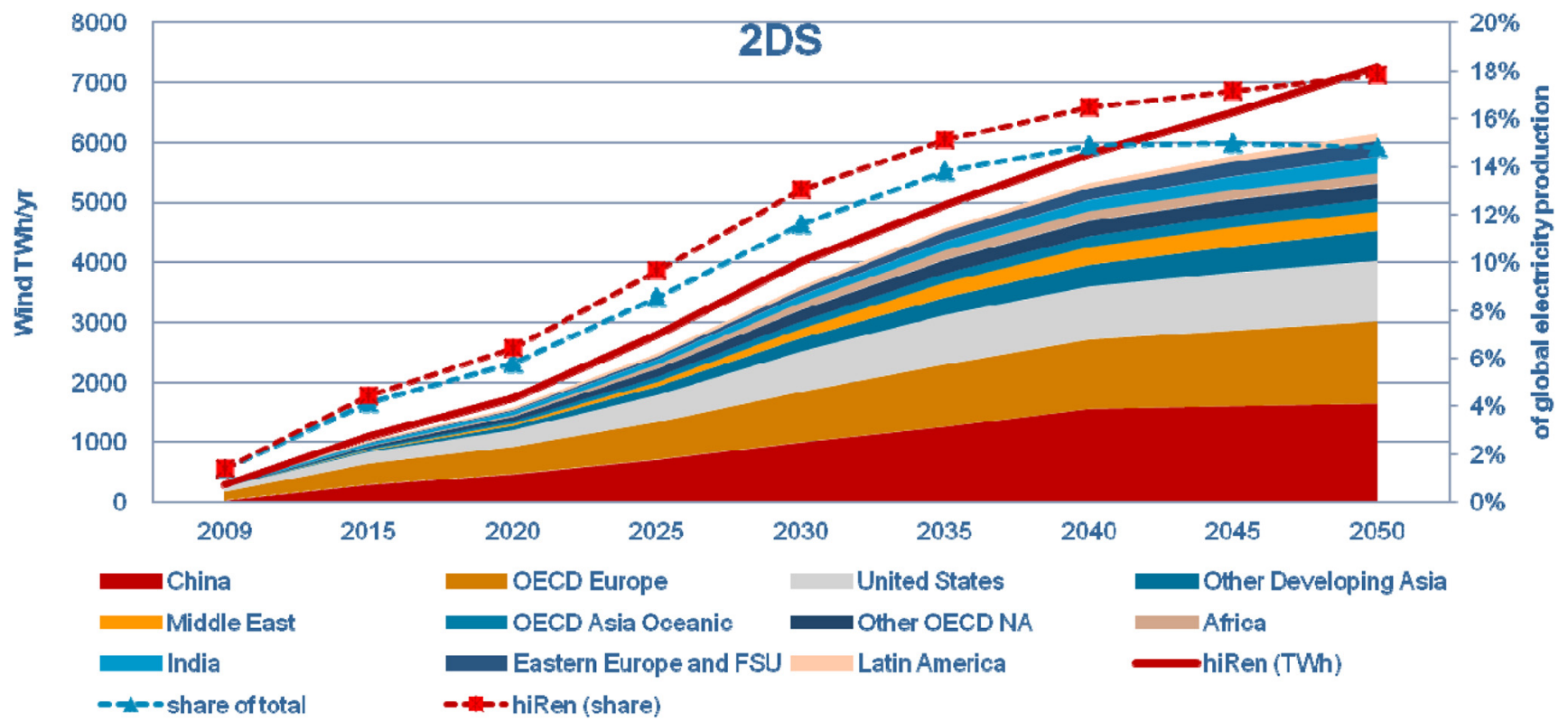

Fig. 5. Wind power deployment to 2050 in the Roadmap vision [9].

Table 1. World electricity demand scenarios 2050 [11].

\begin{tabular}{|c|c|c|c|c|}
\hline \multirow[b]{2}{*}{ Low $(40,000 \mathrm{TWh})$} & \multicolumn{3}{|c|}{ Worldwide electricity demand (TWh/yr) } & \\
\hline & Likely $(57,000 \mathrm{TWh})$ & & High $(74,000 \mathrm{TWh})$ & \multirow[b]{2}{*}{ Wind } \\
\hline 8000 & 12,000 & 16,000 & Low $=20 \%$ & \\
\hline 11,400 & 17,100 & 22,800 & Likely $=30 \%$ & \\
\hline 14,800 & 22,200 & 29600 & High $=40 \%$ & \\
\hline All figures in TWh. & & & & \\
\hline
\end{tabular}



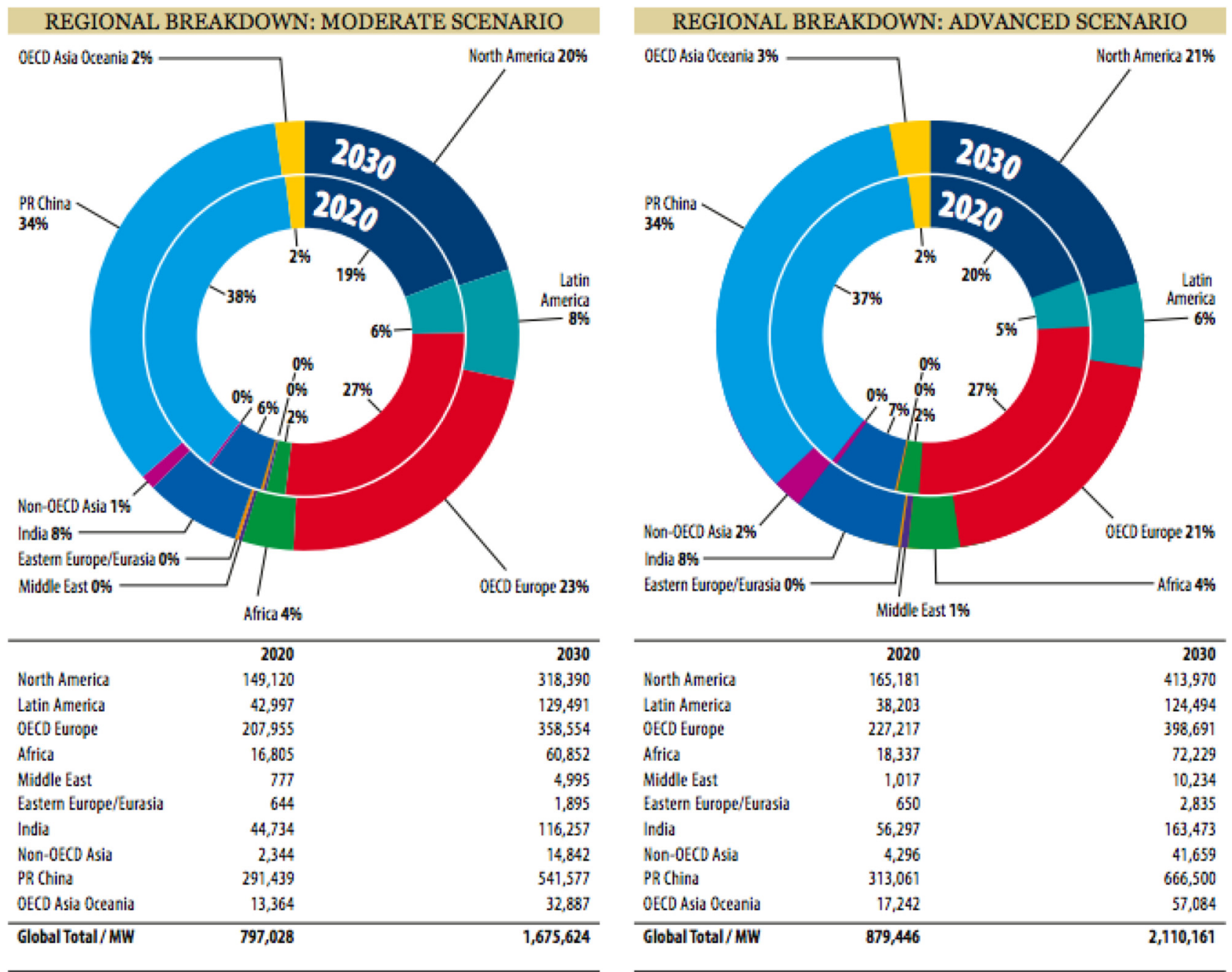

Fig. 6. Moderate and advanced wind energy regional break down scenarios [10].

\section{Energy-related $\mathrm{CO}_{2}$ emissions (Gt/yr)}

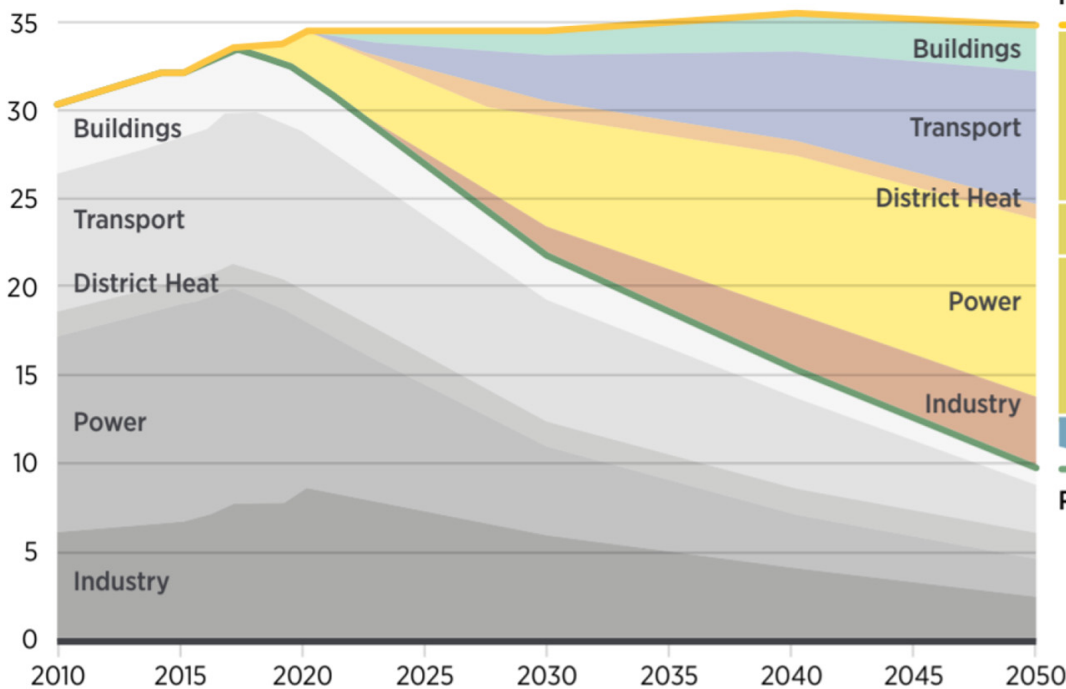

\section{Reference Case: 35 Gt/yr in 2050}

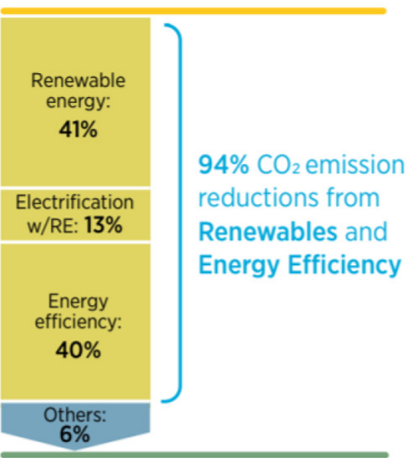

REmap Case: $9.7 \mathrm{Gt} / \mathrm{yr}$ in 2050

Fig. 7. Annual energy-related $\mathrm{CO}_{2}$ emissions and reductions, 2015-2050 (Gt/yr) [12]. 


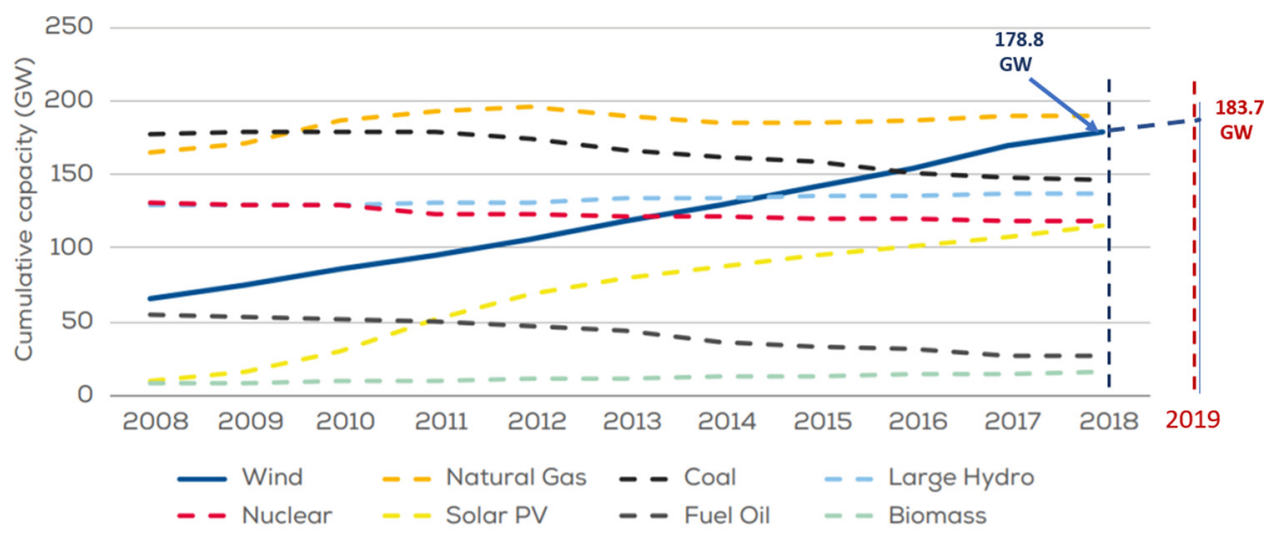

Source: WindEurope

Fig. 8. Total power generation capacity in the European Union 2008-2018 [13].

Table 2. Installed wind power in Europe 2019 [14].

\begin{tabular}{ll}
\hline Onshore & MW \\
\hline France & 523 \\
Sweden & 459 \\
Germany & 287 \\
Italy & 286 \\
Ukraine & 262 \\
Turkey & 229 \\
Greece & 201 \\
UK & 187 \\
Spain & 148 \\
Netherlands & 83 \\
Belgium & 72 \\
Portugal & 57 \\
Ireland & 51 \\
Russia & 50 \\
Bosnia and Herzegovina & 36 \\
Poland & 17 \\
Austria & 16 \\
Croatia & 10 \\
Denmark & 6 \\
Total & $\mathbf{2 , 9 7 9}$ \\
\hline Offshore & MW \\
\hline UK & 931 \\
Denmark & 374 \\
Belgium & 370 \\
Germany & 252 \\
Total & $\mathbf{1 , 9 2 7}$ \\
\hline
\end{tabular}

Total Onshore and Offshore $=4.9 \mathrm{GW}$

- Governance: The European Commission should make sure that the Member States deliver the 27\% target post2020 period.
Macro economic benefits of wind energy under WindEurope's 2030 scenarios
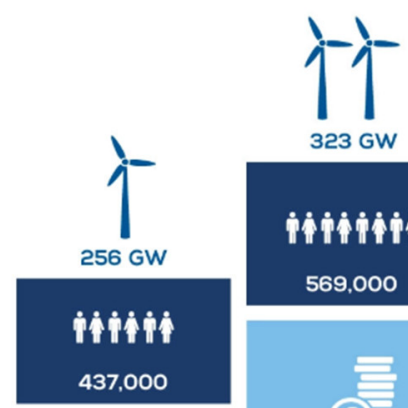
$323 \mathrm{GW}$
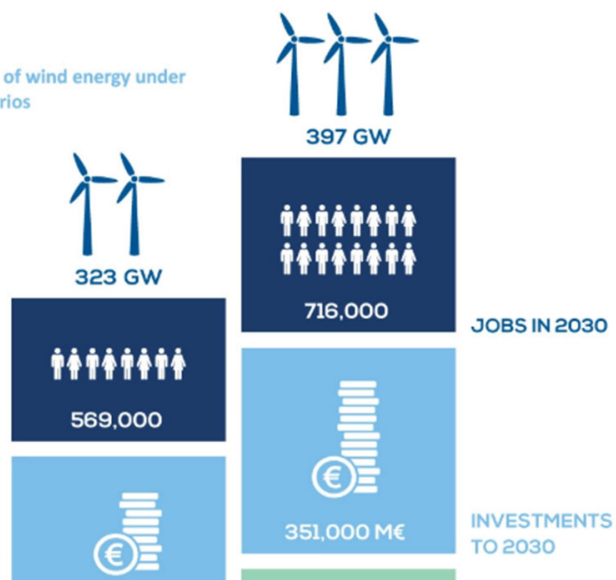

INVESTMENTS
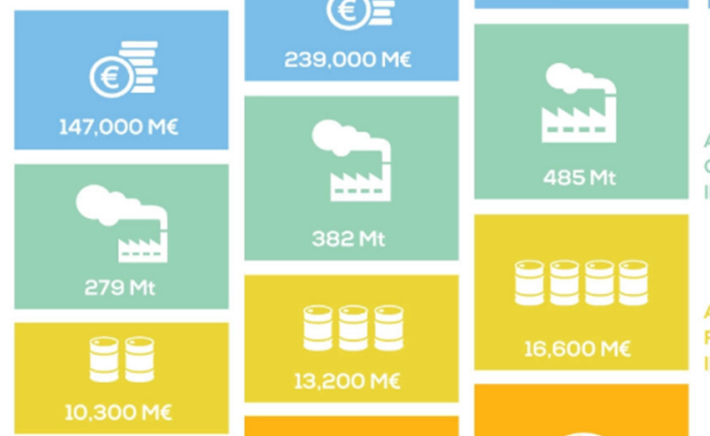
2030
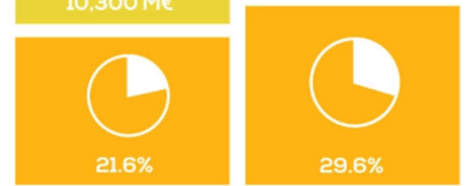

LOW

SCENARIO

CENTRAL

SCENARIO

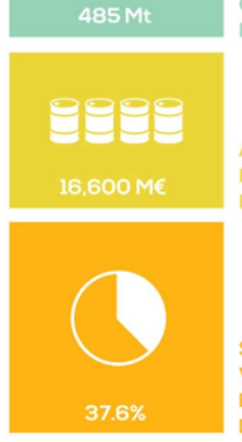

AVOIDED CO, EMISSIONS IN 2030

Fig. 9. Macro economic benefits of wind energy [16].

- Market design: In order to drive larger renewable energies penetration price signals should drive a wellfunctioning power market.

- Renewable Energy Directive: Renewables Directive will be responsible for the post-2020 to deliver the binding EU renewable energy target for 2030. 
Table 3. EWEA 2030 scenarios: capacity installed, power generation and percentage Of EU electricity demand met.

\begin{tabular}{|c|c|c|c|c|c|c|c|c|c|}
\hline & \multicolumn{2}{|c|}{ Installations (GW) } & \multirow[b]{2}{*}{ Total } & \multicolumn{2}{|c|}{ Generation (TWh) } & \multirow[b]{2}{*}{ Total } & \multicolumn{3}{|c|}{ EU electricity demand Met by wind energy (\%) } \\
\hline & Onshore & Offshore & & Onshore & Offshore & & Onshore & Offshore & Total \\
\hline Low scenario & 206.3 & 44.6 & 250.9 & 440.2 & 164.5 & 604.5 & $13.8 \%$ & $5.2 \%$ & $19 \%$ \\
\hline High scenario & 294.0 & 98.1 & 392.1 & 627. & 360.8 & 988.3 & $19.7 \%$ & $11.3 \%$ & $31 \%$ \\
\hline
\end{tabular}

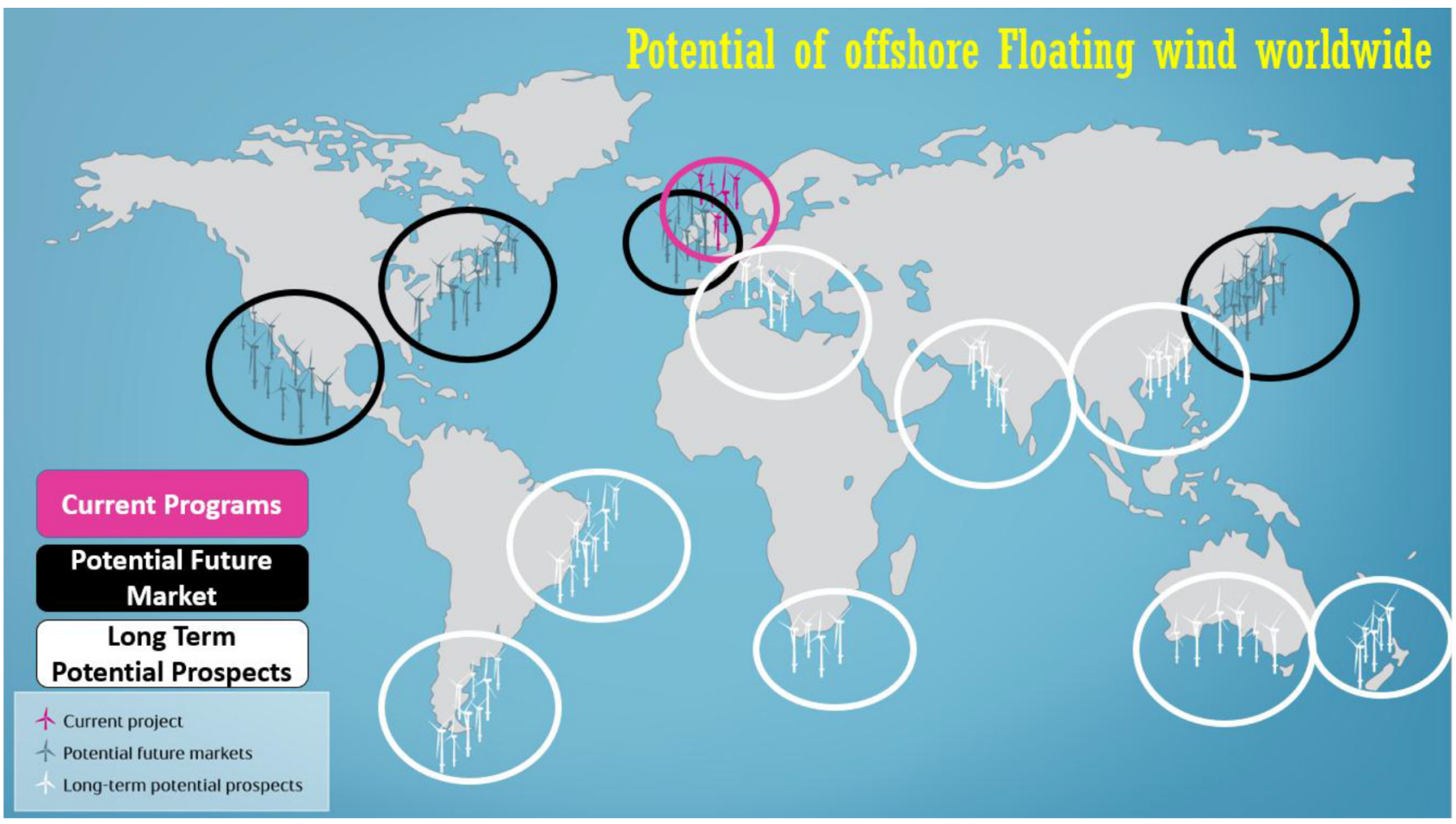

Fig. 10. Shows map shows the vast potential of offshore wind worldwide [18].

- Emission Trading System (ETS): Provide an incentive for investments in renewable energies by reforming the Emission Trading System providing free allocation.

Capacity installed, power generation and percentage of European electricity demand met by wind energy is expected to be $24 \%$ as shown in Table 3 [15].

\section{Europe 2030 economic benefits scenarios of wind energy}

Other scenarios were worked out for the future of wind energy utilization in Europe [16]. The central scenario Figure 9, shows that the total installed capacity by 2030 will be $323 \mathrm{GW}$ and it will provide 569,000 jobs with 239,000 $\mathrm{m} €$ investments. Avoided $\mathrm{CO}_{2}$ emissions are estimated to be around $382 \mathrm{Mt}$ and avoided fossil fuel is $13,200 \mathrm{M} €$ and share of the electricity demand $24-29 \%$.

\section{Floating wind technology}

Offshore wind technology is receiving more interest from investors and in specifically the floating wind turbines for several reasons. The cost of offshore wind falling steeply and will keep doing so. Another reason is that higher and steadier wind speeds are available in deeper waters. The potential of offshore floating wind worldwide is shown in Figure 10 [17]. The floating wind turbines are utility-scale and cost-effective energy sources that experience lower offshore wind turbulence enjoying longer farm life $\sim 25-30$ years. In addition, connection to the electric grid by subsea AC or HVDC cables becomes cheaper, easier and can easily utilize the experience of oil industry floating technology which has made floating turbine installation more efficient. Floating wind technology has a reduced near the coast and onshore wind farms related problems such as the eyesore on the landscape, poor wind speeds onshore, noise pollution, visual impact and species such as birds and bats may also be affected by wind turbines. 


\section{Conclusions}

It is concluded from this research that with appropriate investment in renewables, the world can achieve $100 \%$ clean energy production by 2050 . With the cost of wind turbines has fallen by nearly $1 / 3$ rd since 2009 , it is believed that the wind has the potential to provide $20 \%$ of global electricity production in 2030, creating 2.4 million new jobs and reducing $\mathrm{CO}_{2}$ emissions by more than 3.3 billion tonnes per year. Worldwide wind capacity reached $645 \mathrm{GW}$ in 2019. If the right investment and the anticipated proper implementation of a renewable energy system, renewable energy and energy efficiency can provide over $90 \%$ of the reduction in energy-related $\mathrm{CO}_{2}$ emissions. Offshore wind turbines are the vision of our future technology and the floating wind turbine will have major implications.

\section{References}

1. IRENA, REthinking Energy 2017: Accelerating the global energy transformation. International Renewable Energy Agency, Abu Dhabi (2017).

2. K.P. Rukikaire, Renewable energy investment. Retrieved from UN Environment (2019) https://www.unenvironment. org/news-and-stories/press-release/renewable-energy-invest ment-2018-hit-usd-2889-billion-far-exceeding

3. R. Secretariat, Renewable 2019-Global Status Report (REN21, Paris, 2019)

4. W. e.V., Global Statistics. Retrieved from Wind Energy International (2018). Available https://library.wwindea. org/

5. Get-invest.eu. (2019). Global Market Outlook 2019-2023. Retrieved from get-invest.eu: http://www.solarpowereu rope.org/wp-content/uploads/2019/05/SolarPower-EuropeGlobal-Market-Outlook-2019-2023.pdf

6. IEA, Energy Technology Perspectives (International Energy Agency, 2014)

7. C.L. Archer, M.Z. Jacobson, Spatial and temporal distributions of US winds and wind power at $80 \mathrm{~m}$ derived from measurements, J. Geophys. Res. Atmos. 108 (2003)
8. L. Fried, Wind Power to dominate power sector growth (2016). Retrieved from Global Wind Energy Council: https://gwec.net/wind-power-to-dominate-power-sectorgrowth/

9. F.S. Energy, Cédric PHILIBERT Energy and Climate Change Analyst IEA (Atoms for the Future 2013) (2013). Retrieved from SlideShare: https://www.slideshare.net/ SFEN/cdric-philibert-energy-and-climate-change-analyst-ieaatoms-for-the-future?from_action=save

10. D. Weston, GWEC envisages 5.8TW of wind by 2050 (2016). Retrieved from Wind Power Monthly: https://www.wind powermonthly.com/article/1412717/gwec-envisages-58twwind-2050

11. J. Hossain, Wind Energy 2050 on the shape of near $100 \%$ RE grid. World Wind Energy Association (2015)

12. IRENA, Global Energy Transformation: A roadmap to 2050 , International Renewable Energy Agency, Abu Dhabi (2018). Available ONLINE: https://www.irena.org/-/media/Files/ IRENA/Agency/Publication/2018/Apr/IRENA_Report_ GET_2018.pdf

13. Wind Europe, WIND ENERGY IN EUROPE IN 2018 Trend and Statistics (Wind Europe, Belgium, 2018). Available ONLINE: https://windeurope.org/about-wind/statistics/eu ropean/wind-energy-in-europe-in-2018/

14. Wind Europe, Europe installs $4.9 \mathrm{GW}$ of new wind energy capacity in first half of 2019 (2019). Retrieved from Wind Europe: https://windeurope.org/newsroom/press-releases/ europe-installs-4-9-gw-of-new-wind-energy-capacity-in-firsthalf-of-2019/

15. E.W. Association, Wind energy scenarios for 2030. EWEA (2015). Available Online https://www.ewea.org/fileadmin/ files/library/publications/reports/EWEA-Wind-energy-sce narios-2030.pdf

16. Wind Europe, Wind energy in Europe, Scenarios for 2030 (2017). Retrieved from Wind Europe: https://windeurope. org/about-wind/reports/wind-energy-in-europe-scenariosfor-2030/

17. Equinor, Equinor - the world's leading floating offshore wind developer (2019). Retrieved from equinor: https://www. equinor.com/en/what-we-do/hywind-where-the-wind-takesus.html

18. M. Froese, World's first floating wind farm delivers promising results (2018). [online] Windpower Engineering \& Development. Available at: https://www.windpowerengineering. com/worlds-first-floating-wind-farm-delivers-promisingresults / [Accessed 10 January 2020]

Cite this article as: Abdul Salam Darwish, Riadh Al-Dabbagh, Wind energy state of the art: present and future technology advancements, Renew. Energy Environ. Sustain. 5, 7 (2020) 